\title{
Inhibitory regulation of dendritic activity in vivo
}

\author{
Lucy Palmer 1,2, Masanori Murayama ${ }^{3}$ and Matthew Larkum ${ }^{2 *}$ \\ 1 Institute for Physiology, University of Bern, Bern, Switzerland \\ ${ }^{2}$ NeuroCure Cluster of Excellence, Humboldt University, Berlin, Germany \\ ${ }^{3}$ Behavioral Neurophysiology Lab, Brain Science Institute, Riken, Saitama, Japan
}

Edited by:

Jessica Cardin, Yale University School of Medicine, USA

Reviewed by:

C. J. Heckman, Northwestern University, USA

David J. Margolis, University of

Zurich, Switzerland

*Correspondence:

Matthew Larkum, NeuroCure Center

of Excellence, Humboldt University,

Charitéplatz 1, D-10117 Berlin,

Germany.

e-mail: matthew.larkum@gmail.com
The spatiotemporal control of neuronal excitability is fundamental to the inhibitory process. We now have a wealth of information about the active dendritic properties of cortical neurons including axonally generated sodium action potentials as well as local sodium spikelets generated in the dendrites, calcium plateau spikes, and NMDA spikes. All of these events have been shown to be highly modified by the spatiotemporal pattern of nearby inhibitory input which can drastically change the output firing mode of the neuron. This means that particular populations of interneurons embedded in the neocortical microcircuitry can more precisely control pyramidal cell output than has previously been thought. Furthermore, the output of any given neuron tends to feed back onto inhibitory circuits making the resultant network activity further dependent on inhibition. Network activity is therefore ultimately governed by the subcellular microcircuitry of the cortex and it is impossible to ignore the subcompartmentalization of inhibitory influence at the neuronal level in order to understand its effects at the network level. In this article, we summarize the inhibitory circuits that have been shown so far to act on specific dendritic compartments in vivo.

Keywords: inhibition, interneuron, dendrite, cortex
Understanding a neural network requires knowledge of both the connectivity (anatomy) and the firing properties (physiology) of the embedded neurons (Figure 1A). To unravel neocortical microcircuits, the emphasis has historically been on mapping the architecture (Felleman and Van Essen, 1991; Binzegger et al., 2004; Helmstaedter et al., 2011; Kleinfeld et al., 2011; Figure 1B). Although network connectively determines potential neuronal interactions, the dynamic nature of networks can only be revealed by also including details about the physiological firing properties of individual neurons (De Schutter et al., 2005; Markram, 2006; Izhikevich and Edelman, 2008). Three decades of research on dendritic properties have shown that the individual neurons are themselves astoundingly complex, with multiple sites of spike initiation, and complex interactions between these sites (Llinás, 1988; Wong and Stewart, 1992; Magee, 2000; Heady et al., 2001; Schiller and Schiller, 2001; Häusser and Mel, 2003; Gulledge et al., 2005; London and Häusser, 2005; Spruston, 2008). In particular, the principal neuronal type of the neocortex, the pyramidal neuron (Nieuwenhuys, 1994), can sustain local sodium, calcium, and NMDA spikes which undergo complex spatiotemporal interactions (Figure 1C; Larkum et al., 2009). In to this equation comes the attempt to understand the role of inhibitory neurons of the neocortex which are tremendously diverse (Petilla Interneuron Nomenclature Group et al., 2008). Although they are less numerous than pyramidal neurons (Meyer, 2011; Meyer et al., 2011) interneurons connect more densely to other neurons (Fino and Yuste, 2011) and can therefore match the influence of excitatory neurons in the cortical microcircuit (Wehr and Zador, 2003; Okun and Lampl, 2008; Renart et al., 2010). Particular inhibitory cell types have been shown to have dramatic effects on overall network activity (Cardin et al., 2009; Sohal et al., 2009) and recent developments in optogenetic approaches promise to accelerate our knowledge of the contribution to network function by cortical interneurons (Cardin et al., 2010; Cardin, 2011; Lovett-Barron et al., 2012). Neocortical inhibitory neurons tend to have simpler dendritic arbors than pyramidal neurons and direct dendritic recordings to date have failed to indicate the same level of ion channel diversity and subcellular spiking mechanisms that have been found in pyramidal neuron dendrites (Martina et al., 2000; Markram et al., 2004). On the other hand, the axonal arborizations of interneurons tend to be very complex and their output firing patterns differ tremendously (Petilla Interneuron Nomenclature Group et al., 2008). Of particular interest to the subject of this review, however, is the diversity and precision with which their axons target particular subregions of the pyramidal cell dendritic tree (Kawaguchi, 1995; Thomson and Lamy, 2007; Douglas and Martin, 2009; Druga, 2009).

Taken together, this means that the task of understanding the role of particular inhibitory neurons embedded within the neocortical microcircuit must therefore take into account a number of aspects simultaneously (Figure 1C). (1) Location of synaptic input and dendritic morphologies of cortical inhibitory neurons (Dantzker and Callaway, 2000; Markram et al., 2004; Cruikshank et al., 2007; Xu and Callaway, 2009; Lee et al., 2010; Kubota et al., 2011; Meyer, 2011; Meyer et al., 2011), (2) firing properties (Petilla Interneuron Nomenclature Group et al., 2008), and (3) axonal projections and their subcellular target regions (Kätzel et al., 2011; Meyer et al., 2011). In this review we highlight a fourth and generally under-appreciated aspect: (4) the specific local effects mediated within the dendritic tree due to the interaction of inhibition with active local dendritic properties. 


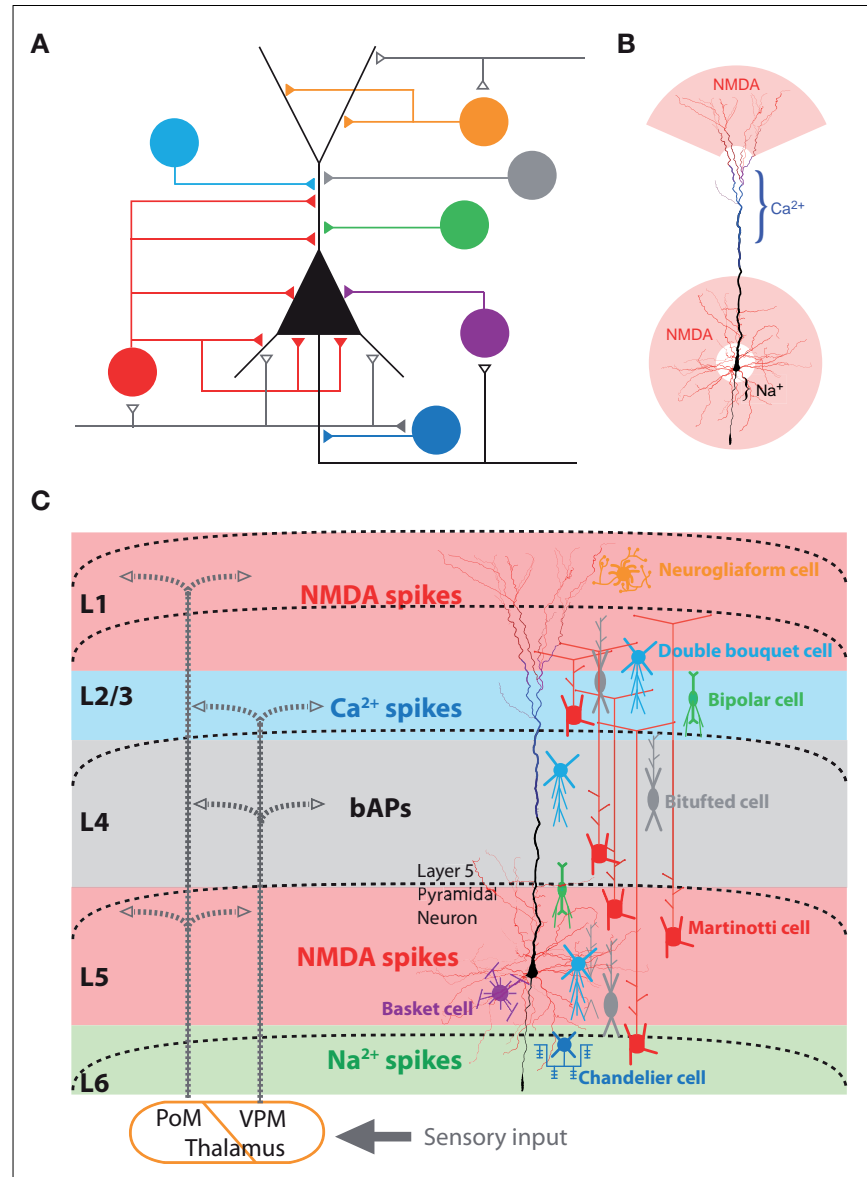

FIGURE 1 | Sources of dendritic inhibition on neocortical pyramidal neurons. (A) Various inhibitory cell types and their axonal target regions on the pyramidal neuron's dendritic tree. Adapted from (Benardo and Wong, 1995). (B) Electrogenic regions of the layer 5 neocortical pyramidal neurons. The dendritic regions which generate NMDA spike (red), $\mathrm{Ca}^{2+}$ spikes (blue), and $\mathrm{Na}^{2+}$ spikes (black) are color-coded (Larkum et al., 2009). (C) Schematic of the cortical network showing the relationship between long-range excitatory synaptic input, axonal projections of inhibitory neurons, and the layer 5 pyramidal neuron with its local electrogenic properties. Interneuron subclasses known to target dendrites and axons are schematically illustrated according to their layer specific distribution (colors corresponding to A). Seen from this perspective, axon terminations in different cortical lamina are likely to have specific influences on different spiking mechanisms within the pyramidal neurons [NMDA spike (red), $\mathrm{Ca}^{2+}$ spikes (blue), backpropagating APs (black), and axonal $\mathrm{Na}^{2+}$ spikes (green)].

\section{FORMS OF DENDRITIC INHIBITION IN THE CORTEX}

As the explosion of molecular and imaging techniques occurred over the past 20 years, so too has our understanding of different sources of inhibition in the cortex. However, our understanding of which cortical inhibitory neurons provide dendritic inhibition and exactly where they synapse on to the dendritic tree is far from complete (DeFelipe, 2002; Markram et al., 2004; Petilla Interneuron Nomenclature Group et al., 2008). In particular, the functional connectivity (i.e., the influence of dendritic inhibition) has not yet been established in its entirety. In fact, it is not even clear whether the main effect is always inhibitory (Gulledge and Stuart, 2003; Glickfeld et al., 2009). Part of the problem is one of nomenclature and designating features that should be considered categorical (Petilla Interneuron Nomenclature Group et al., 2008). In this respect, while still formidable, the study of inhibitory microcircuits is more tractable in the hippocampus because of the simpler overall structure (Klausberger, 2009). Nonetheless, it is quite likely that most or all of the dendrite-targeting inhibitory neurons of the hippocampus have their counterparts in the neocortex (Thomson and Lamy, 2007).

It is not the purpose of this review to provide a systematic overview of all dendrite-targeting neurons complete with defining characteristics such as their anatomy, immunocytochemistry, and firing properties, but rather to explore the role of dendritic inhibition in cortical circuits and in particular the specific effect on pyramidal neuron firing within the cortical circuit. With regard to this second point, it is worth remarking that their diversity and precision of targeting suggests that each interneuronal type serves a particular function in the neocortical circuitry. This specificity also appears to be matched at the molecular level where specific receptors aggregate. Dendritic shafts and spines have both $\mathrm{GABA}_{\mathrm{A}}$ and $\mathrm{GABA}_{\mathrm{B}}$ receptors (Figure $2 \mathrm{~A}$ ). $\mathrm{GABA}_{\mathrm{B}}$ receptors are also found on the presynaptic terminal but are composed of different subunits to the postsynaptic dendritic $G_{A B A}$ receptors (Vigot et al., 2006). The $\mathrm{GABA}_{\mathrm{B} 1 \mathrm{~b}}$-containing receptors found in the apical dendrites of layer 5 (L5) pyramidal neurons (PérezGarci et al., 2006), open G-protein coupled inward rectifying $\mathrm{K}^{+}$channels (GIRKs) and block both $\mathrm{Ca}^{2+}$ channels (Scholz and Miller, 1991; Campbell et al., 1993; Mintz and Bean, 1993; Pérez-Garci et al., 2006; Chalifoux and Carter, 2011; Palmer et al., 2012) and NMDA channels (Chalifoux and Carter, 2010). This means that $\mathrm{GABA}_{\mathrm{B}}$ receptor-activation can be segregated and act specifically either on synaptic transmission or on dendritic electrogenesis. In the larger context, this implies that the cortical inhibitory circuitry is matched closely to subcellular molecular machinery.

\section{TWO KNOWN MICROCIRCUITS INVOLVING DENDRITIC INHIBITION (FIGURE 2)}

The advent of optogenetic approaches is transforming our understanding of the contribution of specific subtypes of inhibitory neurons to cortical network behavior because, for the first time, it is now possible to activate or inactivate a particular cell type (Cardin, 2011; Atallah et al., 2012; Lovett-Barron et al., 2012). Nonetheless, assessing the inhibitory influence at the dendritic level requires a range of approaches. Because of the complexity of cortical network dynamics, it can be easier to empirically measure the effects of activating parts of the network (regions, cell types or physiological stimuli) in vivo rather than predicting their activation from targeted recordings in vitro. So far, two cortical microcircuits involving dendritic inhibition have been uncovered using the in vivo approach. One circuit involves deeplayer Martinotti neurons and the other layer 1 neurogliaform cells. While both cell types act on the apical dendrites of pyramidal neurons, they are recruited under different circumstances and act via different mechanisms. Both these inhibitory microcircuits were uncovered during the investigation of pyramidal cell dendritic properties in vivo highlighting the importance of inhibitory control in cortical networks. 
A

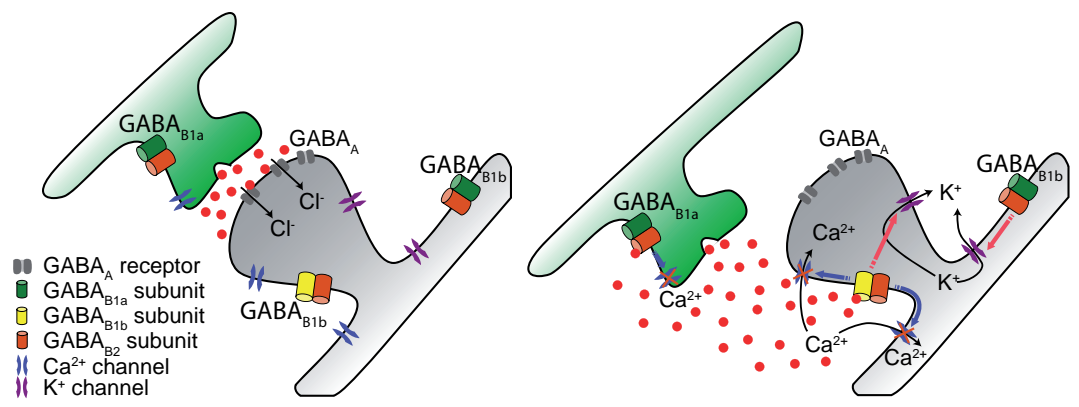

B

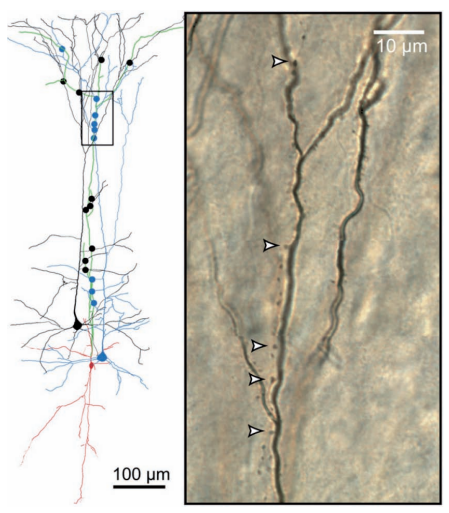

D

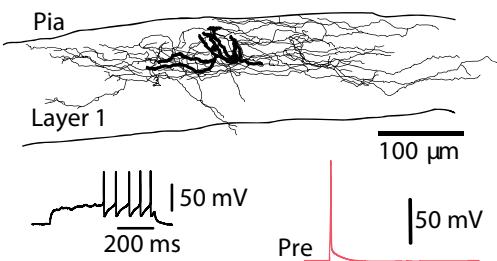

C
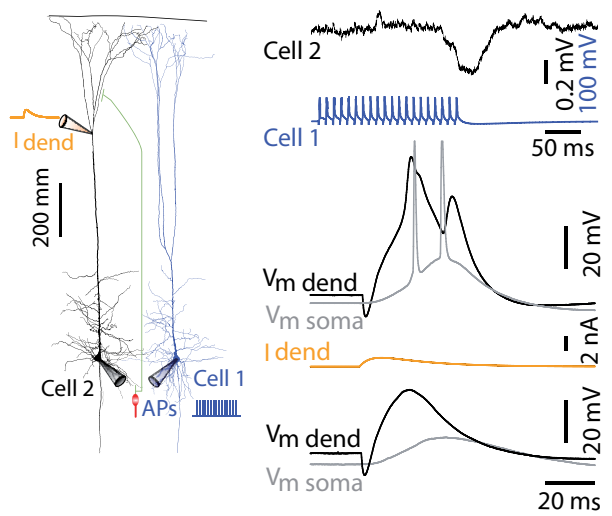

E
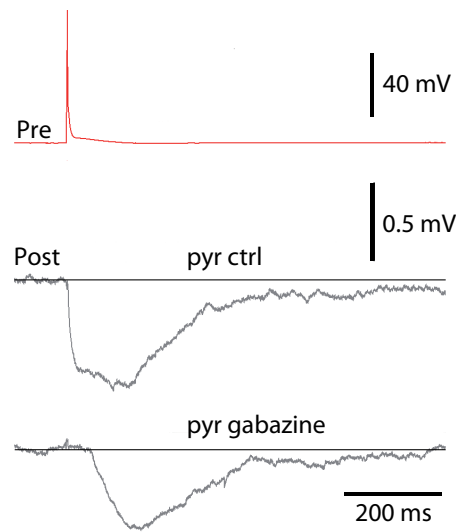

FIGURE 2 |Types of dendritic inhibition. (A) lonotropic, $G A B A_{A}$ inhibition shunts the dendrites and spines via conductance of $\mathrm{Cl}^{-}$and $\mathrm{HCO}_{3}$ ions. $\mathrm{GABA}_{\mathrm{B}}$ receptors on the other hand, which operate metabotropically, have a range of actions and locations. Presynaptically, one isoform of the receptor tends to block $\mathrm{Ca}^{2+}$ channels responsible for triggering the release mechanism. Postsynaptically, a different isoform of the GABA receptor opens $\mathrm{G}$-protein activated inwardly rectifying $\mathrm{K}^{+}$channels and blocks $\mathrm{Ca}^{2+}$ and NMDA channels that control dendritic electrogenesis. $\mathrm{GABA}_{\mathrm{B}}$ receptors are found extrasynaptically where they are involved in "volume transmission" and tonic inhibition. (B) Martinotti neurons have been shown to mediate disynaptic inhibition between neocortical pyramidal neurons. Their apical dendrite targets the dendritic initiation zones of nearby pyramidal neurons (Silberberg and Markram, 2007). (C) Top, repetitive activation of Martinotti neurons causes brief and small hyperpolarizing potentials in the dendrites of pyramidal neurons but $\mathrm{Ca}^{2+}$ spikes generated by local dendritic depolarization (middle) are still powerfully blocked by $\mathrm{GABA}_{\mathrm{A}}$-mediated dendritic inhibition (bottom) because of the profound block of the underlying mechanisms for $\mathrm{Ca}^{2+}$ spikes (Murayama et al., 2009). (D) Late-spiking neurogliaform neurons of layer 1 also target the dendrites of cortical pyramidal neurons (Chu et al., 2003). (E) Neurogliaform cells mediate a large fraction of their inhibitory action on the dendrites through $\mathrm{GABA}_{B}$ receptors (Oláh et al., 2007).

\section{GABA $_{A}$-MEDIATED DENDRITIC INHIBITION VIA MARTINOTTI} NEURONS

The Martinotti neuron was first described over a century ago (Martinotti, 1890) and is distinguished by its axon which extends vertically through the cortical layers ramifying extensively only in layer 1 (Kawaguchi and Kubota, 1996; Figure 2B). Since it receives facilitatory synaptic input from nearby pyramidal neurons (Wang et al., 2004; Kapfer et al., 2007; Silberberg and Markram, 2007), 
it is maximally recruited by burst firing in these neurons (Berger et al., 2010). Network activity leading to bursts in pyramidal neurons therefore disynaptically inhibits the calcium spike initiation zone in the same or neighboring pyramidal cells (Murayama et al., 2009; Figure 2C). Various suggestions have been made as to the function of this circuitry, from synchronizing pyramidal cell activity (Berger et al., 2010) to controlling their sensitivity and dynamic range (Kapfer et al., 2007; Murayama et al., 2009; see also Figure 3). Since the dendritic $\mathrm{Ca}^{2+}$ spike itself leads to bursting in pyramidal neurons (Schwindt and Crill, 1999; Williams and Stuart, 1999), this circuitry may also be a "winner-take-all" mechanism in which the first pyramidal neurons to be recruited above a threshold frequency prevent neighboring pyramidal neurons from joining in. Interestingly, the effects of Martinotti neurons on dendritic $\mathrm{Ca}^{2+}$ activity were found to be mediated almost entirely via $\mathrm{GABA}_{\mathrm{A}}$ receptors in vivo (Murayama et al., 2009).

\section{GABA $_{B}$-MEDIATED INTERHEMISPHERIC INHIBITION}

About $30-40 \%$ of layer 1 (L1) interneurons are neurogliaform cells (Hestrin and Armstrong, 1996; Chu et al., 2003) with a dense axonal arbor mostly confined to L1 (Kubota et al., 2011; Figure 2D). Because of this arrangement, they can only provide inhibition to other interneurons within L1 (Oláh et al., 2007, 2009) or to the distal dendrites of pyramidal neurons (Oláh et al., 2007; Wozny and Williams, 2011). They are notable for responding with a long delay to threshold current injection (Chu et al., 2003; Tamás et al., 2003) and for their disproportionately large influence on pyramidal neuron dendrites via $\mathrm{GABA}_{\mathrm{B}}$ receptors

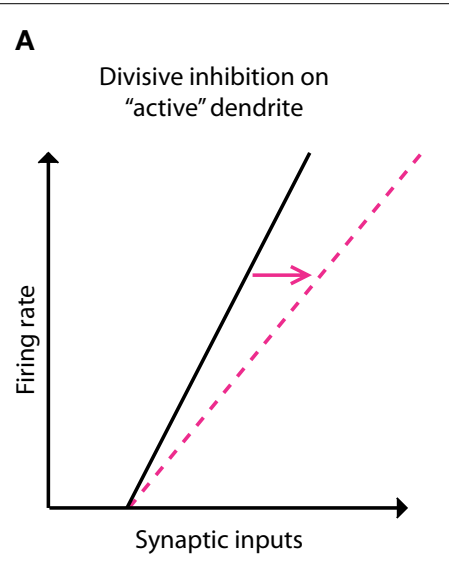

C

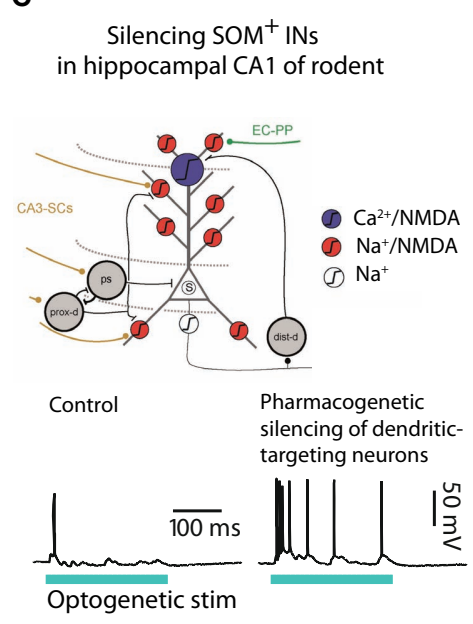

Subtractive inhibition on "passive" dendrite

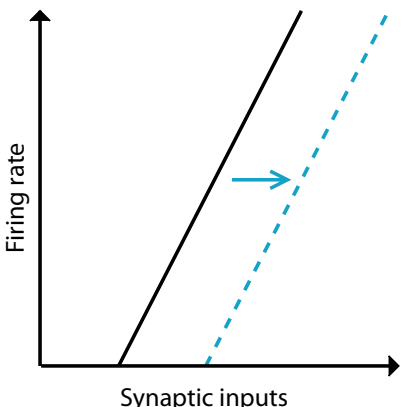

Synaptic inputs
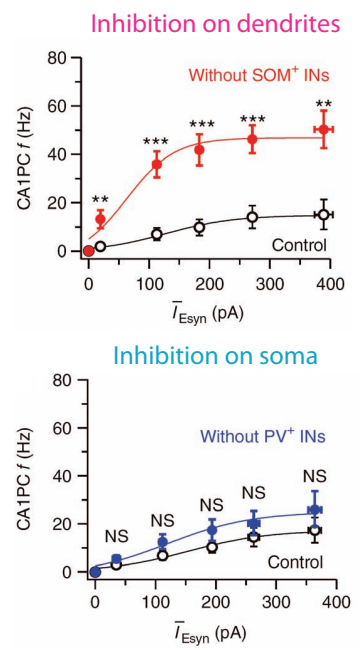

B

Neural circuit in the ELL of gymnotiform fish
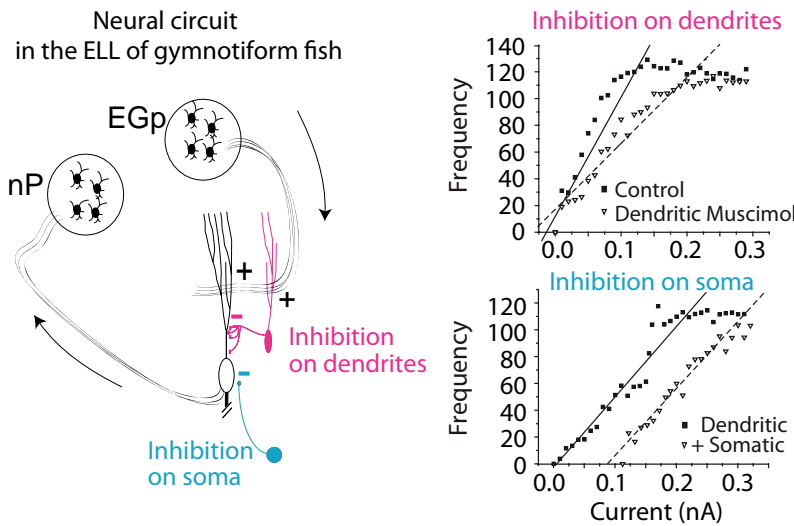

D

Neural circuit in the neocortex of rodent

Inhibition on dendrites
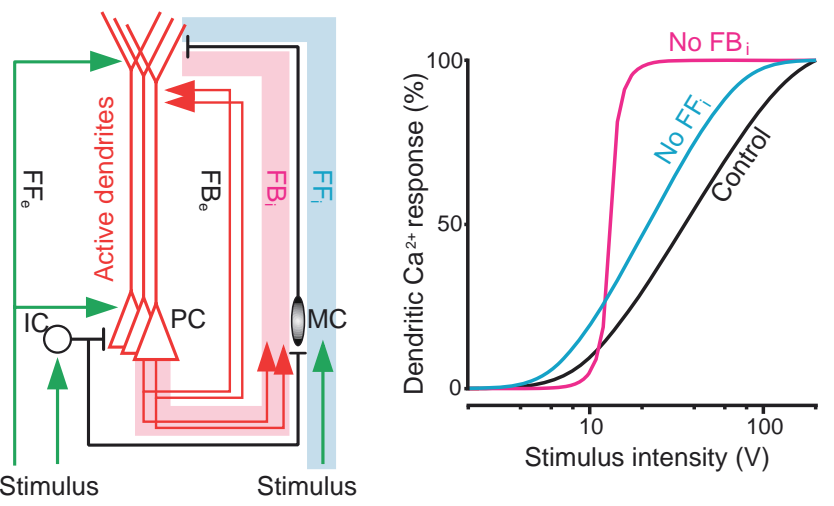

FIGURE 3 | Gain control via dendritic inhibition. (A) It has been postulated that inhibition of active dendritic conductances might act divisively, altering the slope or the gain of the $f / /$ curve whereas inhibition of passive dendrites or somas would be predicted to be subtractive (simply shifting the curve, i.e., raising the threshold; Holt and Koch, 1997). Several systems reliant on pyramidal neurons have confirmed this hypothesis. (B) In the electric fish, one pathway (nP) targets the perisomatic region whereas another, feedback pathway (EGp) targets their active dendrites. A clear difference can be measured in terms of divisive versus subtractive inhibition in this system. Adapted from (Mehaffey et al.

2005). (C) Similarly, in the mammalian hippocampus, synaptic input is segregated on the dendritic trees of CA1 neurons where dendritic targeting somatostatin-positive inhibitory neurons have been shown to perform gain modulation whereas more proximal parvalbumin-positive neurons have negligible effect on gain. Adapted from (Lovett-Barron et al., 2012). (D) A similar effect of dendritic targeting, somatostatin-positive, Martinotti neurons of the neocortex was found from recordings in anesthetized rats. Here, deep-layer Martinotti neurons activated in a feedback loop with local L5 pyramidal neurons, control the gain of the $\mathrm{f} / \mathrm{I}$ curve (Murayama et al., 2009). 
(Tamás et al., 2003; Oláh et al., 2009; Wozny and Williams, 2011), although they also mediate inhibition via $\mathrm{GABA}_{\mathrm{A}}$ receptors (Oláh et al., 2007; Figure 2E). A recent study in vivo points to their likely activation via callosal fibers (Palmer et al., 2012) arising from ipsilateral sensory stimulation (see also Figure 4) which probably recruits this specific subpopulation but not other L1 interneurons. The influence of neurogliaform $\mathrm{GABA}_{\mathrm{B}}$-mediated inhibition on pyramidal cell firing is remarkable given the negligible affect on membrane potential (Palmer et al., 2012). Whereas the subthreshold effect is hardly detectable at the cell body, this form of interhemispheric inhibition reduces the average firing frequency of L5 pyramidal neurons by $25 \%$. In fact, reductions of up to $75 \%$ were achieved with complete activation of local dendritic $G_{A B A}$ receptors via application of a $G A B A_{B}$ receptor agonist. This study not only highlighted the importance of $\mathrm{GABA}_{\mathrm{B}}$-mediated inhibition but also demonstrated that dendritic conductances play a large role in determining the output of cortical pyramidal neurons.

\section{TIMING AND DENDRITIC INHIBITION}

With respect to neuronal computation, timing is everything. Neurons must receive input within a given temporal window in order to achieve maximal integration and summation (for a review, see Dan and Poo, 2004). Because of the filtering of electrical signals in
A

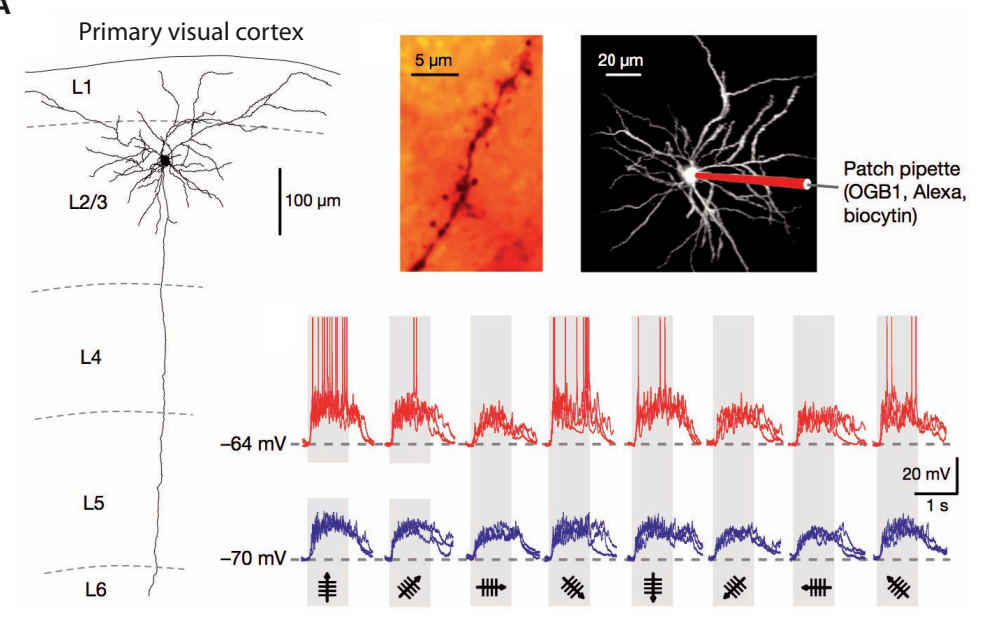

B

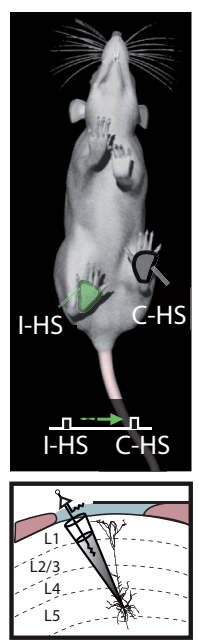

C

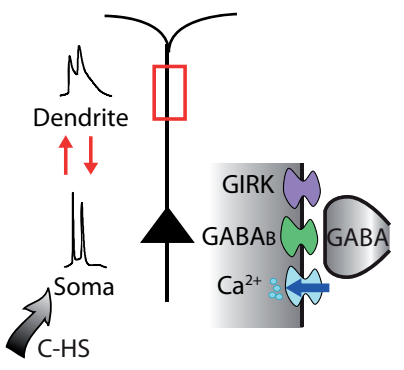

D

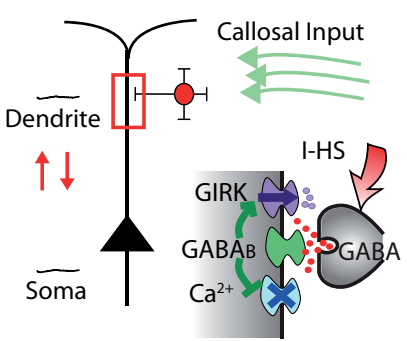

$\mathbf{E}$

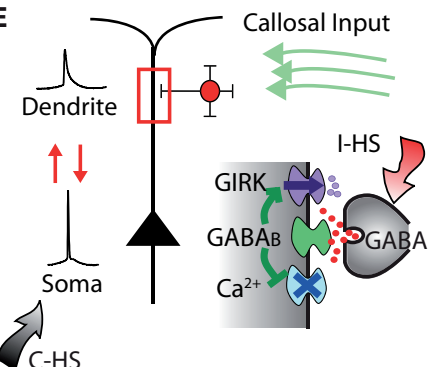

FIGURE 4 | Silent inhibition. (A) The tuning of subthreshold responses in cortical neurons driven by synaptic input in response to sensory stimuli can sometimes look very different to the suprathreshold spiking output which tends to be more narrowly tuned. In layer 2 pyramidal neurons of the visual cortex in mice, differently oriented visual stimuli cause very subtle differences in subthreshold responses but wildly different AP firing (Jia et al., 2010). (B) A similar phenomenon has been shown in somatosensory cortex of rodents where paired ipsi- and contralateral hindlimb stimuli (P-HS) lead to identical subthreshold responses to contralateral hindlimb stimuli (C-HS) alone whereas as spike output is different (Palmer et al., 2012). (C) In the somatosensory case, at least, it could be shown definitively that the difference was due to a form of dendritic $\mathrm{GABA}_{B}$-mediated silent inhibition. This comes about because the inhibitory action is predominately on voltage-sensitive dendritic conductances. Without dendritic inhibition, AP firing in the neuron activates dendritic conductances which contribute to the integrative process in the production of subsequently generated APs. (D) Dendritic inhibition in the absence of cell firing opens dendritic $\mathrm{K}^{+}$channels which have a very weak influence on the soma but their blocking action on dendritic $\mathrm{Ca}^{2+}$ channels is hidden or silent because these channels are closed anyway in the absence of dendritic depolarization. (E) Only during cell firing can the absence of the contribution from dendritic conductances be observed. Adapted from (Palmer et al., 2012). 
the dendrite, the temporal and spatial effects of inhibition intermingle with the precise timing of action potentials in the network (Pouille and Scanziani, 2001; Glickfeld and Scanziani, 2006) and the precise location of synapses on the dendritic tree (Sjöström and Häusser, 2006; Letzkus et al., 2011). This has been powerfully demonstrated in CA1 pyramidal neurons of the hippocampus where inhibitory input shifts from the soma to the dendrite depending on the timing and firing rate of the pyramidal neuron (Pouille and Scanziani, 2004). In addition, the kinetics of the different GABA receptors differ greatly, which also strongly determines their network influence. The effects of $\mathrm{GABA}_{\mathrm{A}}$-mediated inhibition last tens of milliseconds (Galarreta and Hestrin, 1997) whereas metabotropic $\mathrm{GABA}_{\mathrm{B}}$ receptor activation can last for hundreds of milliseconds (Newberry and Nicoll, 1984; Gähwiler and Brown, 1985; Benardo, 1994; Shao and Burkhalter, 1999; Tamás et al., 2003). Therefore the timing of $\mathrm{GABA}_{A}$-mediated inhibition needs to be more exact than $\mathrm{GABA}_{\mathrm{B}}$ mediated inhibition to effect the specific input patterns and processing of input onto dendrites. $\mathrm{GABA}_{\mathrm{B}}$ receptor activation can also occur on a much longer time scale by the activation of extrasynaptic receptors (Oláh et al., 2009; Agnati et al., 2010; Wang et al., 2010).

Inhibitory and excitatory interactions are also best captured in vivo and can now be triggered by activation of subclasses or areas of cortex (Adesnik and Scanziani, 2010; Olsen et al., 2012). For example, specific optogenetic excitation of layer 2/3 (L2/3) pyramidal neurons causes oscillatory activity in these neurons which is dependent on their interaction with local inhibitory neurons. These kinds of interactions clearly also have a spatial dimension because, when combined with cell firing, this specific form of activation led to suppression of activity in L2/3 pyramidal neurons and facilitation of activity in L5 pyramidal neurons (Adesnik and Scanziani, 2010). While this complex behavior is dependent on interactions between excitatory and inhibitory neurons and presumably also involves different target sites (since only the dendrites of L5 pyramidal neurons are present in L2/3), it is not yet clear which inhibitory neurons were recruited. However, this example illustrates that the possible combinations of excitatory and inhibitory interactions in the neocortex are formidable and a priori predictions are extremely difficult. Moreover, since anesthetics used in many in vivo experiments (including the one described above) have a profound effect both on inhibition (Franks and Lieb, 1994) and dendritic properties (Potez and Larkum, 2008), it is likely that dendritic inhibition and network activity are also extremely dependent on the state of consciousness of the animal.

Since dendritic inhibition exhibits such a powerful block of $\mathrm{Ca}^{2+}$ electrogenesis (Larkum et al., 1999; Pérez-Garci et al., 2006), it might be suggested that such local events should be perpetually blocked in vivo where one would expect a constant background firing of inhibitory neurons. However, the fact that dendritic $\mathrm{Ca}^{2+}$ activity does occur in vivo (Hirsch et al., 1995; Helmchen et al., 1998, 1999; Tank et al., 1998; Svoboda et al., 1999; Larkum et al., 2002; Murayama et al., 2009; Chen et al., 2011; Kitamura and Häusser, 2011; Rochefort et al., 2011; Varga et al., 2011) makes it likely that special disinhibitory systems exists to release pyramidal neurons from inhibition acting on the dendritic $\mathrm{Ca}^{2+}$ region.

\section{DENDRITIC INHIBITION AND GAIN CONTROL}

Despite the complexity of inhibition in the neocortical network, there are some generalizations that appear to be emerging. For instance, it has been shown in several systems that dendritically located inhibition can change the slope (gain) of the firing frequency versus synaptic input in pyramidal neurons (Figure 3). In a classic study, Holt and Koch (1997) showed counter intuitively that shunting inhibition should not change the gain of a neuron. This was predicated on the assumption that the inhibition occurred in a passive system with no active conductances (Figure 3A). However, inhibiting the active dendrites of pyramidal neurons in electric fish (Mehaffey et al., 2005; Figure 3B), and CA1 (Lovett-Barron et al., 2012; Figure 3C) and neocortical pyramidal neurons (Murayama et al., 2009; Figure 3D) in rodents can very effectively alter the gain of the neuron. In all these systems, the distal dendrites receive top-down excitatory input that also controls the gain of the neuron (Bernander et al., 1994; Larkum et al., 2004) suggesting that dendritic inhibition may be a mechanism for regulating the influence of feedback or "predictive" information to the neuron (Rao and Ballard, 1999).

The above examples show the importance of considering the role of inhibition within the context of the network architecture in combination with the active properties of the neuron. Other aspects of network function are also important. For instance, in a network with balanced inhibition and excitation, the synaptic noise can start to influence the input-output relation of the neuron such that even somatic and perisomatic inhibition control the gain of the neuron (Chance et al., 2002). Furthermore, when considering the recruitment of neurons throughout the network (related to the threshold synaptic activity for firing), feed-forward perisomatic input can control the dynamic range of the network as a whole (Pouille et al., 2009).

\section{SILENT INHIBITION}

A fundamental feature of neocortical networks is the tuning of individual neurons, for instance orientation in the primary visual cortex (Hubel and Wiesel, 1962) and frequency in the auditory cortex (Merzenich et al., 1975). The fact that each neuron has a receptive field within which it can extract features was originally hypothesized to be dependent on the pattern of inputs it receives. However, in different systems across the cortex, researchers consistently observe that subthreshold input to neurons does not match the suprathreshold output which is typically more differentiated (Figure 4; Bringuier et al., 1999; Carandini and Ferster, 2000; Brecht and Sakmann, 2002; Jia et al., 2010). If the output of the neuron is not entirely determined by its input it follows that the integrative properties of neurons are also crucial to understanding this basic property of cortical networks. One possibility is that fluctuations around threshold account for the tuning properties of neurons, the so-called "iceberg effect" (Rose and Blakemore, 1974; Priebe and Ferster, 2008). Here, considerations of the mechanisms for gain control are important because the iceberg hypothesis appears incompatible with the invariance of tuning to signal strength (Sclar and Freeman, 1982; Sadagopan and Wang, 2008; see Figure 3). For this reason, several researchers have reasoned that inhibition must play an important role in the tuning properties of neurons 
(Frégnac et al., 2003; Shapley et al., 2003; Priebe and Ferster, 2008).

While there is ample evidence that inhibition is fundamental to cortical processing (Sillito, 1975; Borg-Graham et al., 1998; Bruno and Simons, 2002; Wehr and Zador, 2003; Rudolph et al., 2007; Cardin et al., 2009; Douglas and Martin, 2009; Runyan et al., 2010; Isaacson and Scanziani, 2011; Letzkus et al., 2011), there is still much debate about the details and whether it actually contributes to processes such as orientation tuning (Nelson et al., 1994; Ferster et al., 1996; Hofer et al., 2011; Shushruth et al., 2012). Taking into account that further computation can be carried out postsynaptically via active dendritic processes when combinations or clusters of synapses on particular dendritic branches (Mel, 1994; Archie and Mel, 2000; Larkum and Nevian, 2008; Takahashi et al., 2012) activate local dendritic conductances (Branco and Häusser, 2010), it would also be possible for inhibition to contribute in a complex way to these processes. In a recent set of studies, the group of Arthur Konnerth examined synaptic input on to the dendritic trees of L2 neurons with sensory stimuli and found no evidence for local clustering of inputs or dendritic electrogenesis (Jia et al., 2010; Varga et al., 2011; Grienberger et al., 2012; although it has been observed in other systems; Takahashi et al., 2012). Nonetheless, the Konnerth group showed that orientation selectivity as measured by the spiking output of the neurons was intact despite the nearly uniform subthreshold responses (Figure 4A).

What could account for the enormous specificity of output in the face of relatively uniform input? At first glance, inhibition seems to be a poor candidate. In the first place, perisomatic inhibition appears to affect the output firing rate of all neurons uniformly retaining the tuning of the excitatory neurons (Atallah et al., 2012; Olsen et al., 2012). Nevertheless, it has been suggested that the effects of inhibition might be 'silent' and therefore overlooked when measured by conventional methods (Frégnac et al., 2003). Such silent inhibition was recently shown both in vivo and in vitro in the somatosensory cortex of rats. Here, the effects of dendritic inhibition in vivo were undetectable at the cell body (Palmer et al., 2012; Figure 4B). In this instance, it was demonstrated that dendritic inhibition acts on channels that are opened only in the suprathreshold state by the invasion of action potentials

\section{REFERENCES}

Adesnik, H., and Scanziani, M. (2010). Lateral competition for cortical space by layer-specific horizontal circuits. Nature 464, 1155-1160.

Agnati, L. F., Guidolin, D., Guescini, M., Genedani, S., and Fuxe, K. (2010). Understanding wiring and volume transmission. Brain Res. Rev. 64, 137-159.

Archie, K. A., and Mel, B. W. (2000). A model for intradendritic computation of binocular disparity. Nat. Neurosci. 3, 54-63.

Atallah, B. V., Bruns, W., Carandini, M., and Scanziani, M. (2012). Parvalbumin-expressing interneurons linearly transform cortical

from the cell body to the dendrites (Stuart and Sakmann, 1994; Mehaffey et al., 2008; Palmer et al., 2012; Figures 4C-E). This form of dendritic inhibition can shape the computational properties of the neuron and therefore network function while being invisible to standard recording approaches. In the case of orientation selectivity (Jia et al., 2010), for instance, silent inhibition could manifest by shaping the regions of the dendritic tree (and hence the particular synaptic inputs) that could interact with backpropagating APs. In that particular study, hyperpolarization of the cell body was used to prevent APs in order to detect calcium changes in the dendrites that were not contaminated by backpropagating APs. If a form of silent inhibition is involved in the orientation selectivity in these neurons, the suppression of APs could be interpreted as causing the broadening in tuning. However, by its nature, silent inhibition is hard to detect under most situations which makes it difficult to investigate its influence on sensory processing.

\section{CONCLUSION}

Historically, even though they have been shown to have active membranes (Llinás et al., 1968; Kuno and Llinás, 1970; Wong et al., 1979), dendrites were often treated as passive structures and the computational possibilities have tended to be ignored by researchers trying to understand networks and systems. This is nowhere more prevalent than when considering the effects of inhibition at the network level even though evidence for dendritic inhibition goes back several decades (Llinás, 1975; Wong and Prince, 1979; Buzsáki et al., 1996). The common techniques for recording from neurons in vivo, both electrical and optical, generally make statements about dendritic function difficult, however recent advances suggest that the situation is changing. In this review, we have shown the evidence for the importance of considering dendritic inhibition and shown a few examples of where their influence could be demonstrated definitively. We predict that more examples will emerge as more systems are investigated.

\section{ACKNOWLEDGMENTS}

This work was supported by SystemsX.ch (NeuroChoice) and the Swiss National Science Foundation (PP00A-102721 and 31003A_130694).

Bernander, O., Koch, C., and Douglas, R. J. (1994). Amplification and linearization of distal synaptic input to cortical pyramidal cells. J. Neurophysiol.72, 2743-2753.

Binzegger, T., Douglas, R. J., and Martin, K. A. (2004). A quantitative map of the circuit of cat primary visual cortex. J. Neurosci.24, 8441-8453.

Borg-Graham, L. J., Monier, C., and Fregnac, Y. (1998). Visual input evokes transient and strong shunting inhibition in visual cortical neurons. Nature 393, 369-373.

Branco, T., and Häusser, M. (2010). The single dendritic branch as a fundamental functional unit in the nervous system. Curr. Opin. Neurobiol. 20, 494-502.

Brecht, M., and Sakmann, B. (2002). Dynamic representation of whisker deflection by synaptic potentials in spiny stellate and pyramidal cells in the barrels and septa of layer 4 rat somatosensory cortex. J. Physiol. (Lond.)543, 49-70.

Bringuier, V., Chavane, F., Glaeser, L., and Fregnac, Y. (1999). Horizontal propagation of visual activity in the synaptic integration field of area 17 neurons. Science 283, 695-699.

Bruno, R. M., and Simons, D. J. (2002). Feedforward mechanisms of excitatory and inhibitory cortical receptive fields. J. Neurosci. 22, 10966-10975. 
Buzsáki, G., Penttonen, M., Nadasdy, Z., and Bragin, A. (1996). Pattern and inhibition-dependent invasion of pyramidal cell dendrites by fast spikes in the hippocampus in vivo. Proc. Natl. Acad. Sci. U.S.A. 93, 9921-9925.

Campbell, V., Berrow, N., and Dolphin, A. C. (1993). GABAB receptor modulation of $\mathrm{Ca} 2+$ currents in rat sensory neurones by the $\mathrm{G}$ protein $\mathrm{G}(0)$ : antisense oligonucleotide studies. $J$. Physiol. 470, 1-11.

Carandini, M., and Ferster, D. (2000). Membrane potential and firing rate in cat primary visual cortex. J. Neurosci. 20, 470-484.

Cardin, J. A. (2011). Dissecting local circuits in vivo: Integrated optogenetic and electrophysiology approaches for exploring inhibitory regulation of cortical activity. J. Physiol. Paris. doi: 10.1016/j.jphysparis.2011. 09.005

Cardin, J. A., Carlen, M., Meletis, K., Knoblich, U., Zhang, F., Deisseroth, K., Tsai, L. H., and Moore, C. I. (2009). Driving fast-spiking cells induces gamma rhythm and controls sensory responses. Nature 459, 663-667.

Cardin, J. A., Carlen, M., Meletis, K., Knoblich, U., Zhang, F., Deisseroth, K., Tsai, L. H., and Moore, C. I. (2010). Targeted optogenetic stimulation and recording of neurons in vivo using cell-type-specific expression of Channelrhodopsin-2. Nat. Protoc. 5, 247-254.

Chalifoux, J. R., and Carter, A. G. (2010). GABAB receptors modulate NMDA receptor calcium signals in dendritic spines. Neuron 66, 101-113.

Chalifoux, J. R., and Carter, A. G. (2011). GABAB receptor modulation of voltage-sensitive calcium channels in spines and dendrites. $J$. Neurosci. 31, 4221-4232.

Chance, F. S., Abbott, L. F., and Reyes, A. D. (2002). Gain modulation from background synaptic input. Neuron 35, 773-782.

Chen, X., Leischner, U., Rochefort, N. L., Nelken, I., and Konnerth, A. (2011). Functional mapping of single spines in cortical neurons in vivo. Nature $475,501-505$.

Chu, Z., Galarreta, M., and Hestrin, S. (2003). Synaptic interactions of latespiking neocortical neurons in layer 1. J. Neurosci. 23, 96-102.

Cruikshank, S. J., Lewis, T. J., and Connors, B. W. (2007). Synaptic basis for intense thalamocortical activation of feedforward inhibitory cells in neocortex. Nat. Neurosci. 10, 462-468.
Dantzker, J. L., and Callaway, E. M. (2000). Laminar sources of synaptic input to cortical inhibitory interneurons and pyramidal neurons. Nat. Neurosci. 3, 701-707.

Dan, Y., and Poo, M. M. (2004). Spike timing-dependent plasticity of neural circuits. Neuron 44, 23-30.

De Schutter, E., Ekeberg, O., Kotaleski, J. H., Achard, P., and Lansner, A. (2005). Biophysically detailed modelling of microcircuits and beyond. Trends Neurosci. 28, 562-569.

DeFelipe, J. (2002). Cortical interneurons: from Cajal to 2001. Prog. Brain Res. 136, 215-238.

Douglas, R. J., and Martin, K. A. (2009). Inhibition in cortical circuits. Curr. Biol. 19, R398-R402.

Druga, R. (2009). Neocortical inhibitory system. Folia Biol. (Praha) 55, 201-217.

Felleman, D. J., and Van Essen, D. C. (1991). Distributed hierarchical processing in the primate cerebral cortex. Cereb. Cortex 1, 1-47.

Ferster, D., Chung, S., and Wheat, H. (1996). Orientation selectivity of thalamic input to simple cells of cat visual cortex. Nature 380, 249-252.

Fino, E., and Yuste, R. (2011). Dense inhibitory connectivity in neocortex. Neuron 69, 1188-1203.

Franks, N. P., and Lieb, W. R. (1994). Molecular and cellular mechanisms of general anaesthesia. Nature 367, 607-614.

Frégnac, Y., Monier, C., Chavane, F., Baudot, P., and Graham, L. (2003). Shunting inhibition, a silent step in visual cortical computation. J. Physiol. Paris 97, 441-451.

Gähwiler, B. H., and Brown, D. A. (1985). GABAb-receptor-activated $\mathrm{K}+$ current in voltage-clamped CA3 pyramidal cells in hippocampal cultures. Proc. Natl. Acad. Sci. U.S.A. 82, 1558-1562.

Galarreta, M., and Hestrin, S. (1997). Properties of GABAA receptors underlying inhibitory synaptic currents in neocortical pyramidal neurons. J. Neurosci. 17, 7220-7227.

Glickfeld, L. L., Roberts, J. D., Somogyi, P., and Scanziani, M. (2009). Interneurons hyperpolarize pyramidal cells along their entire somatodendritic axis. Nat. Neurosci. 12, 21-23.

Glickfeld, L. L., and Scanziani, M. (2006). Distinct timing in the activity of cannabinoid-sensitive and cannabinoid-insensitive basket cells. Nat. Neurosci. 9, 807-815.

Grienberger, C., Adelsberger, H., Stroh, A., Milos, R. I., Garaschuk, O.,
Schierloh, A., Nelken, I., and Konnerth, A. (2012). Sound-evoked network calcium transients in mouse auditory cortex in vivo. J. Physiol. (Lond.).

Gulledge, A. T., Kampa, B. M., and Stuart, G. J. (2005). Synaptic integration in dendritic trees. J. Neurobiol. 64, 75-90.

Gulledge, A. T., and Stuart, G. J. (2003). Excitatory actions of GABA in the cortex. Neuron 37, 299-309.

Häusser, M., and Mel, B. (2003). Dendrites: bug or feature? Curr. Opin. Neurobiol. 13, 372-383.

Heady, T. N., Gomora, J. C., Macdonald, T. L., and Perez-Reyes, E. (2001). Molecular pharmacology of T-type Ca2+ channels. Jpn. J. Pharmacol. 85, 339-350.

Helmchen, F., Svoboda, K., Denk, W., and Tank, D. W. (1998). Distinct dendritic calcium dynamics in different neocortical pyramidal neurons measured in vivo using twophoton microscopy. Eur. J. Neurosci. 10, 346-346.

Helmchen, F., Svoboda, K., Denk, W., and Tank, D. W. (1999). In vivo dendritic calcium dynamics in deeplayer cortical pyramidal neurons. Nat. Neurosci. 2, 989-996.

Helmstaedter, M., Briggman, K. L., and Denk, W. (2011). High-accuracy neurite reconstruction for highthroughput neuroanatomy. Nat. Neurosci. 14, 1081-1088.

Hestrin, S., and Armstrong, W. E. (1996). Morphology and physiology of cortical neurons in layer I. $J$. Neurosci. 16, 5290-5300.

Hirsch, J. A., Alonso, J. M., and Reid, R. C. (1995). Visually evoked calcium action-potentials in cat striate cortex. Nature 378, 612-616.

Hofer, S. B., Ko, H., Pichler, B., Vogelstein, J., Ros, H., Zeng, H., Lein, E., Lesica, N. A., and Mrsic-Flogel, T. D. (2011). Differential connectivity and response dynamics of excitatory and inhibitory neurons in visual cortex. Nat. Neurosci. 14, 1045-1052.

Holt, G. R., and Koch, C. (1997). Shunting inhibition does not have a divisive effect on firing rates. Neural. Comput. 9, 1001-1013.

Hubel, D. H., and Wiesel, T. N. (1962). Receptive fields, binocular interaction and functional architecture in the cat's visual cortex. J. Physiol. (Lond.) 160, 106-154.

Isaacson, J. S., and Scanziani, M. (2011). How inhibition shapes cortical activity. Neuron 72, 231-243.

Izhikevich, E. M., and Edelman, G. M. (2008). Large-scale model of mammalian thalamocortical systems. Proc. Natl. Acad. Sci. U.S.A. 105, 3593-3598.

Jia, H., Rochefort, N. L., Chen, X. and Konnerth, A. (2010). Dendritic organization of sensory input to cortical neurons in vivo. Nature 464, 1307-1312.

Kapfer, C., Glickfeld, L. L., Atallah, B. V., and Scanziani, M. (2007). Supralinear increase of recurrent inhibition during sparse activity in the somatosensory cortex. Nat. Neurosci. 10, 743-753.

Kätzel, D., Zemelman, B. V., Buetfering, C., Wölfel, M., and Miesenböck, G. (2011). The columnar and laminar organization of inhibitory connections to neocortical excitatory cells. Nat. Neurosci. 14, 100-107.

Kawaguchi, Y. (1995). Physiological subgroups of nonpyramidal cells with specific morphological characteristics in layer II/III of rat frontal cortex. J. Neurosci. 15, 2638-2655.

Kawaguchi, Y., and Kubota, Y. (1996). Physiological and morphological identification of somatostatin- or vasoactive intestinal polypeptidecontaining cells among GABAergic cell subtypes in rat frontal cortex. $J$. Neurosci. 16, 2701-2715.

Kitamura, K., and Häusser, M. (2011). Dendritic calcium signaling triggered by spontaneous and sensoryevoked climbing fiber input to cerebellar Purkinje cells in vivo. $\mathrm{J}$. Neurosci. 31, 10847-10858.

Klausberger, T. (2009). GABAergic interneurons targeting dendrites of pyramidal cells in the CA1 area of the hippocampus. Eur. J. Neurosci. 30, 947-957.

Kleinfeld, D., Bharioke, A., Blinder, P., Bock, D. D., Briggman, K. L., Chklovskii, D. B., Denk, W., Helmstaedter, M., Kaufhold, J. P., Lee, W. C., Meyer, H. S., Micheva, K. D., Oberlaender, M., Prohaska, S., Reid, R. C., Smith, S. J., Takemura, S., Tsai, P. S., and Sakmann, B. (2011). Largescale automated histology in the pursuit of connectomes. J. Neurosci. 31, 16125-16138.

Kubota, Y., Shigematsu, N., Karube, F., Sekigawa, A., Kato, S., Yamaguchi, N., Hirai, Y., Morishima, M., and Kawaguchi, Y. (2011). Selective coexpression of multiple chemical markers defines discrete populations of neocortical GABAergic neurons. Cereb. Cortex 21, 1803-1817.

Kuno, M., and Llinás, R. (1970). Enhancement of synaptic transmission by dendritic potentials in chromatolysed motoneurones of cat. $J$. Physiol. (Lond.) 210, 807-821. 
Larkum, M. E., and Nevian, T. (2008). Synaptic clustering by dendritic signalling mechanisms. Curr. Opin. Neurobiol. 18, 321-331.

Larkum, M. E., Nevian, T., Sandler, M., Polsky, A., and Schiller, J. (2009). Synaptic integration in tuft dendrites of layer 5 pyramidal neurons: a new unifying principle. Science 325 , 756-760.

Larkum, M. E., Senn, W., and Lüscher, H. R. (2004). Top-down dendritic input increases the gain of layer 5 pyramidal neurons. Cereb. Cortex 14, 1059-1070.

Larkum, M. E., Zhu, J. J., and Sakmann, B. (1999). A new cellular mechanism for coupling inputs arriving at different cortical layers. Nature 398, 338-341.

Larkum, M. E., and Zhu, J. J. (2002). Signaling of layer 1 and whiskerevoked $\mathrm{Ca}^{2+}$ and $\mathrm{Na}^{+}$action potentials in distal and terminal dendrites of rat neocortical pyramidal neurons in vitro and in vivo. J. Neurosci. 22, 6991-7005.

Lee, S., Hjerling-Leffler, J., Zagha, E., Fishell, G., and Rudy, B. (2010). The largest group of superficial neocortical GABAergic interneurons expresses ionotropic serotonin receptors. J. Neurosci. 30, 16796-16808.

Letzkus, J. J., Wolff, S. B., Meyer, E. M., Tovote, P., Courtin, J., Herry, C., and Luthi, A. (2011). A disinhibitory microcircuit for associative fear learning in the auditory cortex. Nature 480, 331-335.

Llinás, R. (1975). Electroresponsive properties of dendrites in central neurons. Adv. Neurol. 12, 1-13.

Llinás, R., Nicholson, C., Freeman, J. A., and Hillman, D. E. (1968). Dendritic spikes and their inhibition in alligator Purkinje cells. Science 160, 1132-1135.

Llinás, R. R. (1988). The intrinsic electrophysiological properties of mammalian neurons: insights into central nervous system function. Science 242, 1654-1664.

London, M., and Häusser, M. (2005). Dendritic computation. Annu. Rev. Neurosci. 28, 503-532.

Lovett-Barron, M., Turi, G. F., Kaifosh, P., Lee, P. H., Bolze, F., Sun, X. H., Nicoud, J. F., Zemelman, B. V., Sternson, S. M., and Losonczy, A. (2012). Regulation of neuronal input transformations by tunable dendritic inhibition. Nat. Neurosci. 423-430, S421-423.

Magee, J. C. (2000). Dendritic integration of excitatory synaptic input. Nat. Rev. Neurosci. 1, 181-190.
Markram, H. (2006). The blue brain project. Nat. Rev. Neurosci. 7, 153-160.

Markram, H., Toledo-Rodriguez, M., Wang, Y., Gupta, A., Silberberg, G., and $\mathrm{Wu}, \mathrm{C}$. (2004). Interneurons of the neocortical inhibitory system. Nat. Rev. Neurosci. 5, 793-807.

Martina, M., Vida, I., and Jonas, P. (2000). Distal initiation and active propagation of action potentials in interneuron dendrites. Science 287, 295-300.

Martinotti, C. (1890). Beitrag zum Studium der Hirnrinde und dem Centralursprung der Nerven. Int. Monatsschr. Anat. Physiol. 7, 69-90.

Mehaffey, W. H., Doiron, B., Maler, L., and Turner, R. W. (2005). Deterministic multiplicative gain control with active dendrites. J. Neurosci. 25, 9968-9977.

Mehaffey, W. H., Fernandez, F. R., Doiron, B., and Turner, R. W. (2008). Regulation of somatic firing dynamics by backpropagating dendritic spikes. J. Physiol. Paris 102, 181-194.

Mel, B. W. (1994). Information processing in dendritic trees. Neural. Comput. 6, 1031-1085.

Merzenich, M. M., Knight, P. L., and Roth, G. L. (1975). Representation of cochlea within primary auditory cortex in the cat. J. Neurophysiol. 38, 231-249.

Meyer, H. S., Schwarz, D., Wimmer, V. C., Schmitt, A. C., Kerr, J. N., Sakmann, B., and Helmstaedter, M. (2011). Inhibitory interneurons in a cortical column form hot zones of inhibition in layers 2 and 5A. Proc. Natl. Acad. Sci. U.S.A. 108, 16807-16812.

Meyer, K. (2011). Primary sensory cortices, top-down projections and conscious experience. Prog. Neurobiol. 94, 408-417.

Mintz, I. M., and Bean, B. P. (1993). GABAB receptor inhibition of $\mathrm{P}$ type $\mathrm{Ca} 2+$ channels in central neurons. Neuron 10, 889-898.

Murayama, M., Pérez-Garci, E., Nevian, T., Bock, T., Senn, W., and Larkum, M. E. (2009). Dendritic encoding of sensory stimuli controlled by deep cortical interneurons. Nature 457, 1137-1141.

Nelson, S., Toth, L., Sheth, B., and Sur, M. (1994). Orientation selectivity of cortical neurons during intracellular blockade of inhibition. Science 265, 774-777.

Newberry, N. R., and Nicoll, R. A. (1984). Direct hyperpolarizing action of baclofen on hippocampal pyramidal cells. Nature 308, 450-452.
Nieuwenhuys, R. (1994). The neocortex. An overview of its evolutionary development, structural organization and synaptology. Anat. Embryol. 190, 307-337.

Okun, M., and Lampl, I. (2008). Instantaneous correlation of excitation and inhibition during ongoing and sensory-evoked activities. Nat. Neurosci. 11, 535-537.

Oláh, S., Füle, M., Komlósi, G., Varga, C., Báldi, R., Barzó, P., and Tamás, G. (2009). Regulation of cortical microcircuits by unitary GABA-mediated volume transmission. Nature 461, 1278-1281.

Oláh, S., Komlósi, G., Szabadics, J. Varga, C., Tóth, E., Barzó, P., and Tamás, G. (2007). Output of neurogliaform cells to various neuron types in the human and rat cerebral cortex. Front. Neural Circuits 1:4. doi:10.3389/neuro.04/004.2007

Olsen, S. R., Bortone, D. S., Adesnik, H. and Scanziani, M. (2012). Gain control by layer six in cortical circuits of vision. Nature 483, 47-52.

Palmer, L. M., Schulz, J. M., Murphy, S. C., Ledergerber, D., Murayama, M., and Larkum, M. E. (2012). The cellular basis of GABAB-mediated interhemispheric inhibition. Science 335 989-993.

Pérez-Garci, E., Gassmann, M., Bettler, B., and Larkum, M. E. (2006). The GABAB1b isoform mediates long-lasting inhibition of dendritic $\mathrm{Ca}^{+}{ }^{+}$spikes in layer 5 somatosensory pyramidal neurons. Neuron 50 , 603-616.

Petilla Interneuron Nomenclature Group, Ascoli, G. A., AlonsoNanclares, L., Anderson, S. A., Barrionuevo, G., BenavidesPiccione, R., Burkhalter, A., Buzsáki, G., Cauli, B., Defelipe, J., Fairén, A., Feldmeyer, D., Fishell, G., Fregnac, Y., Freund, T. F., Gardner, D., Gardner, E. P., Goldberg, J. H., Helmstaedter, M., Hestrin, S. Karube, F., Kisvárday, Z. F., Lambolez, B., Lewis, D. A., Marin, O. Markram, H., Muñoz, A., Packer, A., Petersen, C. C., Rockland, K. S., Rossier, J., Rudy, B., Somogyi, P., Staiger, J. F., Tamás, G., Thomson, A. M., Toledo-Rodriguez, M., Wang, Y., West, D. C., and Yuste, R. (2008). Petilla terminology: nomenclature of features of GABAergic interneurons of the cerebral cortex. Nat. Rev. Neurosci. 9, 557-568.

Potez, S., and Larkum, M. E. (2008). Effect of common anesthetics on dendritic properties in layer 5 neocortical pyramidal neurons. J. Neurophysiol. 99, 1461-1477.
Pouille, F., Marin-Burgin, A., Adesnik, H., Atallah, B. V., and Scanziani, M. (2009). Input normalization by global feedforward inhibition expands cortical dynamic range. Nat. Neurosci. 12, 1577-1585.

Pouille, F., and Scanziani, M. (2001). Enforcement of temporal fidelity in pyramidal cells by somatic feedforward inhibition. Science 293, 1159-1163.

Pouille, F., and Scanziani, M. (2004). Routing of spike series by dynamic circuits in the hippocampus. Nature 429, 717-723.

Priebe, N. J., and Ferster, D. (2008). Inhibition, spike threshold, and stimulus selectivity in primary visual cortex. Neuron 57, 482-497.

Rao, R. P., and Ballard, D. H. (1999). Predictive coding in the visual cortex: a functional interpretation of some extra-classical receptive-field effects. Nat. Neurosci. 2, 79-87.

Renart, A., de la Rocha, J., Bartho, P., Hollender, L., Parga, N., Reyes, A., and Harris, K. D. (2010). The asynchronous state in cortical circuits. Science 327, 587-590.

Rochefort, N. L., Narushima, M., Grienberger, C., Marandi, N., Hill, D. N., and Konnerth, A. (2011). Development of direction selectivity in mouse cortical neurons. Neuron 71, 425-432.

Rose, D., and Blakemore, C. (1974). Effects of bicuculline on functions of inhibition in visual cortex. Nature 249, 375-377.

Rudolph, M., Pospischil, M., Timofeev, I., and Destexhe, A. (2007). Inhibition determines membrane potential dynamics and controls action potential generation in awake and sleeping cat cortex. J. Neurosci. 27, 5280-5290.

Runyan, C. A., Schummers, J., Van Wart, A., Kuhlman, S. J., Wilson, N. R. Huang, Z. J., and Sur, M. (2010). Response features of parvalbuminexpressing interneurons suggest precise roles for subtypes of inhibition in visual cortex. Neuron 67, 847-857.

Sadagopan, S., and Wang, X. (2008). Level invariant representation of sounds by populations of neurons in primary auditory cortex. J. Neurosci. 28, 3415-3426.

Schiller, J., and Schiller, Y. (2001) NMDA receptor-mediated dendritic spikes and coincident signal amplification. Curr. Opin. Neurobiol. 11, 343-348.

Scholz, K. P., and Miller, R. J. (1991). GABAB receptor-mediated inhibition of $\mathrm{Ca} 2+$ currents and synaptic transmission in cultured rat 
hippocampal neurones. J. Physiol. 444, 669-686.

Schwindt, P., and Crill, W. (1999). Mechanisms underlying burst and regular spiking evoked by dendritic depolarization in layer 5 cortical pyramidal neurons. J. Neurophysiol. 81, 1341-1354.

Sclar, G., and Freeman, R. D. (1982). Orientation selectivity in the cat's striate cortex is invariant with stimulus contrast. Exp. Brain Res. 46, 457-461.

Shao, Z. W., and Burkhalter, A. (1999). Role of GABA(B) receptor-mediated inhibition in reciprocal interareal pathways of rat visual cortex. J. Neurophysiol. 81, 1014-1024.

Shapley, R., Hawken, M., and Ringach, D. L. (2003). Dynamics of orientation selectivity in the primary visual cortex and the importance of cortical inhibition. Neuron 38, 689-699.

Shushruth, S., Mangapathy, P., Ichida, J. M., Bressloff, P. C., Schwabe, L., and Angelucci, A. (2012). Strong recurrent networks compute the orientation tuning of surround modulation in the primate primary visual cortex. J. Neurosci. 32, 308-321.

Silberberg, G., and Markram, H. (2007). Disynaptic inhibition between neocortical pyramidal cells mediated by Martinotti cells. Neuron 53, 735-746.

Sillito, A. M. (1975). The contribution of inhibitory mechanisms to the receptive field properties of neurones in the striate cortex of the cat. J. Physiol. (Lond.) 250, 305-329.

Sjöström, P. J., and Häusser, M. (2006). A cooperative switch determines the sign of synaptic plasticity in distal dendrites of neocortical pyramidal neurons. Neuron 51, 227-238.

Sohal, V. S., Zhang, F., Yizhar, O., and Deisseroth, K. (2009). Parvalbumin neurons and gamma rhythms enhance cortical circuit performance. Nature 459, 698-702.

Spruston, N. (2008). Pyramidal neurons: dendritic structure and synaptic integration. Nat. Rev. Neurosci. 9, 206-221.

Stuart, G. J., and Sakmann, B. (1994). Active propagation of somatic action-potentials into neocortical pyramidal cell dendrites. Nature 367, 69-72.

Svoboda, K., Helmchen, F., Denk, W., and Tank, D. W. (1999). Spread of dendritic excitation in layer $2 / 3$ pyramidal neurons in rat barrel cortex in vivo. Nat. Neurosci. 2, 65-73.

Tank, D. W., Svoboda, K., Helmchen, F., and Denk, W. (1998). In vivo imaging of dendritic calcium dynamics. J. Gen. Physiol. 112, $6 \mathrm{~A}-6 \mathrm{~A}$.

Takahashi, N., Kitamura, K., Matsuo, N., Mayford, M., Kano, M., Matsuki, N., and Ikegaya, Y. (2012). Locally synchronized synaptic inputs. Science $335,353-356$.

Tamás, G., Lörincz, A., Simon, A., and Szabadics, J. (2003). Identified sources and targets of slow inhibition in the neocortex. Science 299, 1902-1905.

Thomson, A. M., and Lamy, C. (2007) Functional maps of neocortical local circuitry. Front. Neurosci. 1, 19-42.

Varga, Z., Jia, H., Sakmann, B., and Konnerth, A. (2011). Dendritic coding of multiple sensory inputs in single cortical neurons in vivo. Proc. Natl. Acad. Sci. U.S.A. 108, 15420-15425.

Vigot, R., Barbieri, S., Brauner-Osborne, H., Turecek, R., Shigemoto, R., Zhang, Y. P., Lujan, R., Jacobson, L. H., Biermann, B., Fritschy, J. M., Vacher, C. M., Muller, M., Sansig, G., Guetg, N., Cryan, J. F., Kaupmann, K., Gassmann, M., Oertner, T. G., and Bettler, B. (2006). Differential compartmentalization and distinct functions of GABAB receptor variants. Neuron 50, 589-601.

Wang, Y., Neubauer, F. B., Luscher, H. R., and Thurley, K. (2010). GABAB receptor-dependent modulation of network activity in the rat prefrontal cortex in vitro. Eur. J. Neurosci. 31, 1582-1594.

Wang, Y., Toledo-Rodriguez, M., Gupta, A., Wu, C., Silberberg, G., Luo, J. and Markram, H. (2004). Anatomical, physiological and molecular properties of Martinotti cells in the somatosensory cortex of the juvenile rat. J. Physiol. (Lond.) 561, 65-90.

Wehr, M., and Zador, A. M. (2003). Balanced inhibition underlies tuning and sharpens spike timing in auditory cortex. Nature 426 , 442-446.

Williams, S. R., and Stuart, G. J. (1999), Mechanisms and consequences of action potential burst firing in rat neocortical pyramidal neurons. $J$. Physiol. (Lond.) 521, 467-482.

Wong, R. K., and Prince, D. A. (1979). Dendritic mechanisms underlying penicillin-induced epileptiform activity. Science 204, 1228-1231.

Wong, R. K., and Stewart, M. (1992). Different firing patterns generated in dendrites and somata of CA1 pyramidal neurones in guinea-pig hippocampus. J. Physiol. (Lond.) 457, 675-687.

Wong, R. K. S., Prince, D. A., and Basbaum, A. I. (1979). Intra-dendritic recordings from hippocampal neurons. Proc. Natl. Acad. Sci. U.S.A. 76, 986-990.

Wozny, C., and Williams, S. R. (2011) Specificity of synaptic connectivity between layer 1 inhibitory interneurons and layer $2 / 3$ pyramidal neurons in the rat neocortex. Cereb. Cortex 21, 1818-1826.

Xu, X., and Callaway, E. M. (2009). Laminar specificity of functional input to distinct types of inhibitory cortical neurons. J. Neurosci. 29, 70-85.

Conflict of Interest Statement: The authors declare that the research was conducted in the absence of any commercial or financial relationships that could be construed as a potential conflict of interest.

Received: 29 February 2012; accepted: 20 April 2012; published online: 25 May 2012.

Citation: Palmer L, Murayama $M$ and Larkum $M$ (2012) Inhibitory regulation of dendritic activity in vivo. Front. Neural Circuits 6:26. doi: 10.3389/fncir.2012.00026

Copyright (c) 2012 Palmer, Murayama and Larkum. This is an open-access article distributed under the terms of the Creative Commons Attribution Non Commercial License, which permits noncommercial use, distribution, and reproduction in other forums, provided the original authors and source are credited. 